\title{
Ford Motor Company Partners with the University of Toronto
}

University of Toronto research team is working with the Ford Motor Company to develop a new material for car parts using renewable resources extracted from wood pulp in a $\$ 4.9$ million project. The Automotive Partnership Canada (APC), a collaboration of public and private sector members, is supplying \$2 513 500. Financial and inkind contributions from Ford and $U$ of $\mathrm{T}$ bring the total value of the project to $\$ 4981500$, researchers said.

The team, led by Professor Mohini Sain, is using two key ingredients from wood pulp: micro-cellulose fibre and lignin carbon fibre. These two fibres are combined to create a high-strength composite that will be used to manufacture automotive components. The manufacturing process will be greener, and the components lighter, leading to reduced vehicle emissions.

"We are very fortunate to have three leading public-private partners helping us to address a key research issue to design and manufacture automobiles for better living," said Sain, who is dean of the Faculty of Forestry and crossappointed to Chemical Engineering and Applied Chemistry. "We are a committed multidisciplinary team with relevant expertise poised to bring transformative changes in lightweight materials innovation and positively contribute to global climate change by reducing greenhouse gas emissions."
Sain is joined by $\mathrm{U}$ of $\mathrm{T}$ researchers Ramin Farnood of Chemical Engineering and Applied Chemistry, Chandra Veer Singh of Materials Science and Engineering and Ning Yan of Forestry, who is also cross-appointed in Chemical Engineering and Applied Chemistry. Roman Maev of the University of Windsor rounds out the team.

To develop the unique design tools and processing technologies needed to produce their new composite material, researchers are working closely with industry partner Ford Motor Company.

"Congratulations to all the researchers," said Professor Paul Young, $\mathrm{U}$ of T's vice-president (research and innovation). "Collaborative research like this, in which academia and industry join forces, allows us to apply our combined strengths to solving realworld problems."

The project builds on Sain's success innovating the use of natural materials in place of plastic in manufactured goods. An active entrepreneur, Sain's technology formed the basis for the spinoff company Greencore Composites, and he holds several patents.

Announced in April 2009, Automotive Partnership Canada is a five-year, \$145-million initiative that supports collaborative research and development and pushes the Canadian automotive industry to greater levels of innovation. Automotive companies play a key role in this industry-driven initiative, by providing both financial support and essential in-kind contributions to the collaborative research projects.

"The automotive industry has told us how important R\&D partnerships are to innovation in this sector," said Janet Walden, Chief Operating Officer of the Natural Sciences and Engineering Research Council of Canada, which is the lead agency within Automotive Partnership Canada. "Across Canada, Automotive Partnership Canada is supporting industry-university research partnerships that are translating our strong discovery research into new knowledge and technologies that companies tell us help to improve their products, processes and technologies."

Written by Jenny Hall (writer with the office of the vice-president, Research and Innovation)

Source:

http://www.news.utoronto.ca/fordmotor-company-partners-u-t-makegreener-lighter-cars?utm_source=Facebook\&utm_medium=News\&utm_cam paign $=$ Generic

OLD GROWIH * FOREAS ANCIENNES

\section{Southern Alberta Wildfires of 1910}

$\mathrm{n}$ the United States, the Great Fires of 1910 were so significant that the ensuing wildfire management policies provided considerable direction not only to better the development of the United States Forest Service, but also state agencies. The 1910 wildfire events peaked and gained national attention with blowup conditions on August $20^{\text {th }}$ and $21^{\text {st }}$. During what became known as the "Great Blowup", multiple wildfires escaped control, joining each other, burning millions of board feet of forests and reducing several communities to ashes. Eighty-seven people, mostly firefighters, perished in the conflagration. It proved to be the single deadliest event for firefighters up until the September 11,2001 attacks a century later.

The resultant policies had significant impacts on land and forest management 